\title{
A CROSS SECTIONAL STUDY ON LUNG FUNCTIONS IN ATHLETES, SINGERS, AND INDIVIDUALS WITH SEDENTARY LIFESTYLES IN AHMADU BELLO UNIVERSITY, ZARIA
}

\author{
*Imam, M. I., James, J. N., and Akor-Dewu, M. B.
}

Department of Human Physiology, Faculty of Medicine, Ahmadu Bello University, Zaria. *Correspondence author: maryamimam1@yahoo.com, +2348035954577

\begin{abstract}
Physical activity when performed regularly has beneficial effects on the various systems of the body, pulmonary functions inclusive. This study was aimed at determining the effect singing and athletics have on the lung functions as compared to sedentary lifestyle, and whether athletes differ in lung functions from singers in Ahmadu Bello University, Zaria. Anthropometric data was also matched with spirometric parameters. Spirometric parameters: Forced Expiratory Volume in one second (FEV 1 , Forced Vital Capacity(FVC) and the ratio of Forced Expiratory Volume in one second to Forced Vital Capacity(FEV $/$ FVC\%) were assessed in randomly selected 60 healthy, nonsmoking, non-obese male subjects 15-30years of age, that included athletes, singers and sedentary individuals and grouped as such. The mean FEV for singers (3.33 10.11 ) and athletes $3.39 \pm 0.13$ was significantly higher ( $p=0.007$ and $p=0.002$ respectively) than that for sedentary control

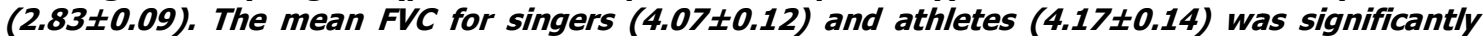
higher ( $p=0.015$ and $p=0.003$ respectively) than that for sedentary group (3.57 \pm 0.11$)$. The difference in means of FEV 1 and FVC between athletes and singers were of no statistical significance. There was no significant difference in the mean FEV $1 / F V C \%$ amongst the groups, $79.68 \pm 1.66,82.40 \pm 2.43$ and $81.63 \pm 2.15$ for sedentary, singers and athletes respectively. Singers and athletes had a higher body weight than sedentary, but the mean age for the sedentary control was higher. In conclusion, the study showed a better pulmonary function in both athletes and singers compared to sedentary control with a positive correlation to weight. Singers did not differ in pulmonary functions when compared to athletes.

Keywords: Athletes, Forced expiratory volume, Forced vital capacity, Singers, Sedentary.
\end{abstract}

\section{INTRODUCTION}

Physical activities in the form of sports and exercise if performed regularly have beneficial effects on the various systems of the body by improving their functions. There is usually an increase in metabolic activities during exercise for instance, therefore the functions of the cardiopulmonary systems is increased, increasing ventilation and cardiac output. Several studies (Belman \& Mittman, 1980; Nourryet al., 2005; Robinson \& Kjedlgaard, 1982; Wassermannet al.,1995) have shown that exercise improves pulmonary function by increasing pulmonary capacity as the strength of respiratory muscles are increased. Similarly, some other studies have shown non-significant change in pulmonary function following exercise (running) (Kuppu Raoet al., 1998;Hamilton\& Andrew, 1976; Doherty\& Dimitriou, 1997) when compared to non-athletes.

Pulmonary ventilation and hence function depends on lung volumes and capacities and mechanics of breathing which is determined by the strength of respiratory muscles, compliance of the chestwall and elastic recoil of the lungs. Pulmonary Function Tests (PFTs) assess defects in airflow (ventilatory functions), lung volumes and gas exchange, and aid in diagnosis and management of respiratory disorders. They (PFTs) provide quantitative and qualitative evaluation of pulmonary function and are therefore of definitive value in the diagnosis and therapy of patients with cardiopulmonary disorders, especially those with obstructive and restrictive lung diseases (Belman \& Mittman, 1980; Robinson \&
Kjeldgard, 1982). The three aspects of PFTs are: (1) Spirometry for assessing air flow (2) spirometric volumes and body plethysmography for measurement of lung volumes and capacities, and (3) testing the diffusing capacity of the lung for carbon monoxide $(D,, C O)$ for assessing gas exchange function. (Ranu et al., 2011).

The parameters used to describe lung functions are lung volumes and capacities. While the various lung volumes reflect the individual's ability to increase the depth of breathing, the capacities is simply a combination of two or more volumes (Adegoke \& Arogundade, 2002). Physiological determinants of lung volumes/capacities are: age, gender, anthropometric measures, ethnicity, altitude and physical activities (Lufti, 2017).

Spirometry is a physiological test that measures how an individual inhales or exhales volumes of air as a function of time and is used as a screening test of general respiratory health. Spirometry assess the integrated mechanical function of the lungs, chestwall, and respiratory muscles by measuring the total volume of air expired from a full lung(Total Lung Capacity $[T L C]$ ) to maximal expiration (Residual Volume $[R V]$ ) and Forced Expiratory Volume in one second $\left(\mathrm{FEV}_{1}\right)$, Forced Vital Capacity (FVC) and $\mathrm{FEV}_{1} / \mathrm{FVC} \%$. Vital capacity (VC) is the maximum volume of air that can be expired from the lungs after maximal inspiration, FVC is the total volume of air expired forcefully with greatest force after maximal inspiration i.e. 
VC with maximal forced expiratory effort. $\mathrm{FEV}_{1}$ is the total volume of air expired in the first second during maximal effort from a position of full inspiration. $\mathrm{FEV}_{1}$ manoeuvres assess abnormalities in airway resistance (in obstructive airway diseases) indirectly. It measures airflow rate, the most useful test to detect generalized airway obstruction. Lung volumes indirectly assess abnormalities of compliance (in restrictive lung diseases). VC indicates strength of respiratory muscles, used to assess the ability of a person to put up maximum inspiration and expiration (Miller et al., 2005b).

FEV1/FVC ratio aid in the identification of obstructive or restrictive ventilatory defects. An obstructive defect is indicated by a low FEV1/FVC ratio (with reduced $\mathrm{FEV}_{1}$ and normal or reduced FVC), which is defined as less than $70 \%$ (GOLD criteria) or below the fifth percentile of predicted value orlower limit of normal(LLN) based on data from the Third National Health and Nutrition Examination Survey (NHANES III) in adults, and less than $85 \%$ in patients 5 to 18 years of age (American Thoracic Society [ATS]). A restrictive pattern is indicated by an FVC below the fifth percentile based on NHANES III data in adults, or less than $80 \%$ in patients 5 to 18 years of age.FEV1/FVC ratio is normal or increased.A low FEV1/FVC ratio and FVC indicates a mixed defect (Pellegrino et al. 2005; Moore, 2012; Vestbo et al. 2013; Johnson \& Theurer, 2014).

Respiration has a key role to play in singing, like the voice or speech which is produced from the vocal cords and involve the use of respiratory structures/muscles and inspiratory and expiratory manoeuvres (Petterson, 2005).Thus, classically trained singers exhibit efficient breath management and greater use of their lung capacity than nonsingers (Collyeret al., 2008).

Both obstructive (OLD) and restrictive lung diseases (RLD) have shown increased prevalence, incidence, morbidity and mortality rate around the world. RLDsare associated with diminished pulmonary compliance while OLDs are characterized by airflow limitation.Sincephysical activities are known to be beneficial to the whole body, and a component of pulmonary rehabilitation especially in obstructive lung diseases like COPD, it could, together with singing serve as adjunct in the therapy of pulmonary diseases. Many studies found a positive correlation between exercise/physical activities and improved lung function but very few studies have investigated the effect singing has on pulmonary function.

This study was aimed at determining the effect singing and athletics have on the lung functions as compared to sedentary lifestyle and whether athletes differ in lung functions from singers using Ahmadu Bello University, Zaria as the study population. Lung functions were also matched with anthropometric indices to see if there is any correlation.

\section{MATERIALS AND METHODS Subjects}

This study was conducted in the Department of Human Physiology, Faculty of Medicine, Ahmadu Bello University Zaria.The study population comprised of athletes, singers and sedentary individuals selected randomly from Ahmadu Bello University, Zaria. Athletic group consisted of runners, footballers, basketball players, and those who play American football, who haveall been into athletics for an average of 9years. Singers were made up of choristers that rehearsed very frequently at a mean of 8.7 years, while sedentary group comprised of subjects with leisure-time physical activity or activities done for less than 20 minutes or fewer than three times per week.Smokers and subjects with contraindications as described in the American Thoracic Society (ATS)/European Respiratory Society (ERS)guidelines and recommendations (Miller et al., 2005a)were exempted from the study.

A total of 60 healthy male volunteers aged 17 to 28 years took part in the study. They were grouped into athletes $(n=20)$, singers $(n=20)$ and sedentary individuals $(n=20)$. The age ofsubjects were estimated to their last birthdays. Informed consent was obtained before commencement of procedures. Information was gathered regarding personal history, smoking,recent respiratory illness, medications used e.t.c. Anthropometric measurements; height in meters $(\mathrm{m})$ and weight in kilogram $(\mathrm{kg})$ of each subject was measured before the test procedure. The Body Mass Indices (BMI) of the subjects were also calculated using the formula: BMI $=$ weight $/$ height $\left(\mathrm{kg} / \mathrm{m}^{2}\right)$.

\section{Pulmonary Function Tests}

Spirometry was carried out with the assistance of a well-trained laboratory technician using the Wedge BellowsVitalograph Spirometer, in accordance with ATS/ERSGuidelines 2005 (Miller et al., 2005b).Each participant was well informed about the instrument and the technique demonstrated prior to commencement of test. Measurements were taken between $11 \mathrm{am}$ and $4 \mathrm{pm}$ to avoid diurnal variations in lung functions.Spirometry was done on all subjects in a standing position.Each subject was asked to take a convenient standing position, then asked to take a deep breath and expire maximally and forcefully into the tube. Parameters analysed are $\mathrm{FEV}_{1}, \mathrm{FVC}$, and $\mathrm{FEV}_{1} / \mathrm{FVC}$ ratio.

\section{STATISTICAL ANALYSIS}

All data were expressed as mean \pm SEM (standard error of mean). Statistical analysis was done using IBM SPSS version 21 (USA). One way analysis of variance (ANOVA) was used to see if the groups differ in any of the parameters followed byTukey post hocmultiple comparison test.P $<0.05$ was considered significant.

\section{RESULTS}

\section{Mean of Anthropometric Indices}

The age in years of the sedentary group was significantly higher than those for athletes as shown on Table 1. Weightsofathletes and singers were significantly higher than those for sedentary group. All groups had similar heights and BMIs.

\section{Pulmonary Function Tests: FEV 1 , FVC and FEV $_{\mathbf{1}} / \mathrm{FVC}_{\mathbf{0}}$}

The mean $\mathrm{FEV}_{1}$ for sedentary control was found to be $2.83 \pm 0.09$, that for singers was $3.33 \pm 0.11$, while that for athletes was $3.39 \pm 0.13$. 
Bajopas Volume 10 Number 2 December, 2017

The mean FVC for sedentary control was found to be $3.57 \pm 0.11$, that for singers was $4.07 \pm 0.12$, while that for athletes was $4.17 \pm 0.14$ The mean $\mathrm{FEV}_{1} / \mathrm{FVC} \%$ for sedentary control was found to be $79.68 \pm 1.66$ that of for singers was $82.40 \pm 2.43$ while that of athletes was $81.63 \pm 2.15$. $\mathrm{FEV}_{1}$ for singers and athletes was significantly higher $(p=0.007$ and $p=0.002$ respectively) than that for sedentary group. FVC for singers and athletes was significantly higher $(p=0.015$ and $p=0.003$ respectively) than that for sedentary group. The difference between athletes and singers was of no statistical significance.The difference among the groups for FEV1/FVC\% were not statistical significant.

Table 1.Mean anthropometric indices for sedentary, singers \&athletes

\begin{tabular}{llll}
\hline Indices & Sedentary $(\mathbf{n = 2 0})$ & Singers $(\mathbf{n = 2 0})$ & Athletes $(\mathbf{n = 2 0})$ \\
\hline Age $($ years $)$ & $24 \pm 0.61^{\mathrm{b}}$ & $23 \pm 0.59$ & $22 \pm 0.56^{*}$ \\
Weight $(\mathrm{kg})$ & $60.25 \pm 1.65$ & $69.10 \pm 2.48^{*}$ & $68.70 \pm 2.30^{*}$ \\
Height $(\mathrm{cm})$ & $173.00 \pm 1.38$ & $181.45 \pm 3.65$ & $180.70 \pm 2.59$ \\
BMI $\left(\mathrm{kg} / \mathrm{m}^{2}\right)$ & $20.13 \pm 0.50$ & $21.01 \pm 0.48$ & $21.02 \pm 0.51$ \\
\hline
\end{tabular}

Data are presented as mean \pm SEM. $*=$ significant difference at $\mathrm{p}<0.05$ compared to sedentary group

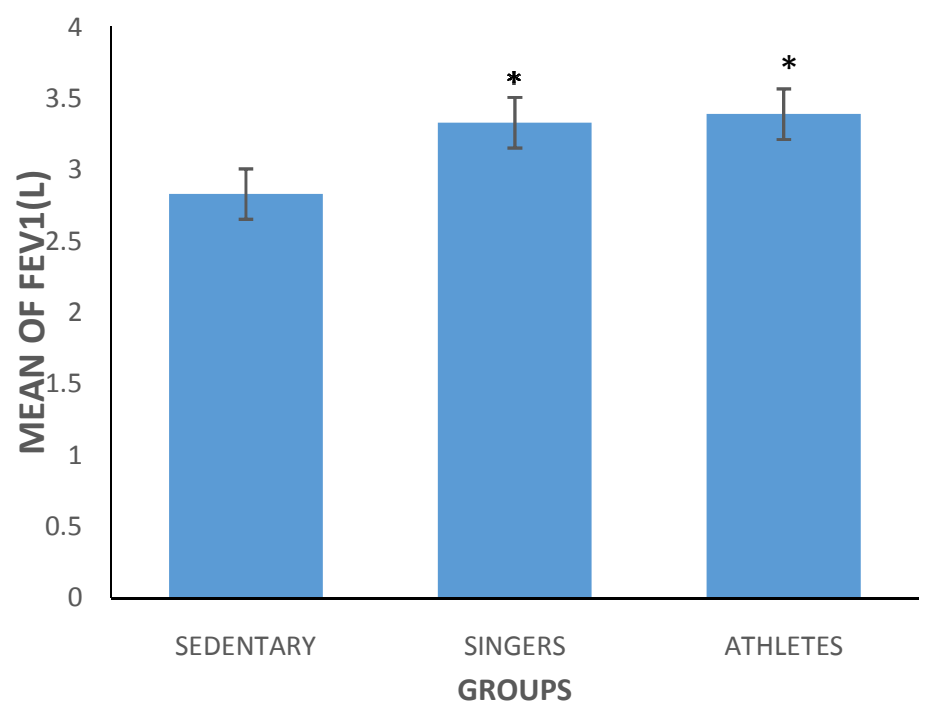

Figure 1: Mean for $\mathrm{FEV}_{1}$ among sedentary, singers and athletes.Values presented as mean $\pm \mathrm{SEM}, \mathrm{n}=20 .^{*}=$ Significant difference at $\mathrm{P}<0.05$ compared to sedentary group

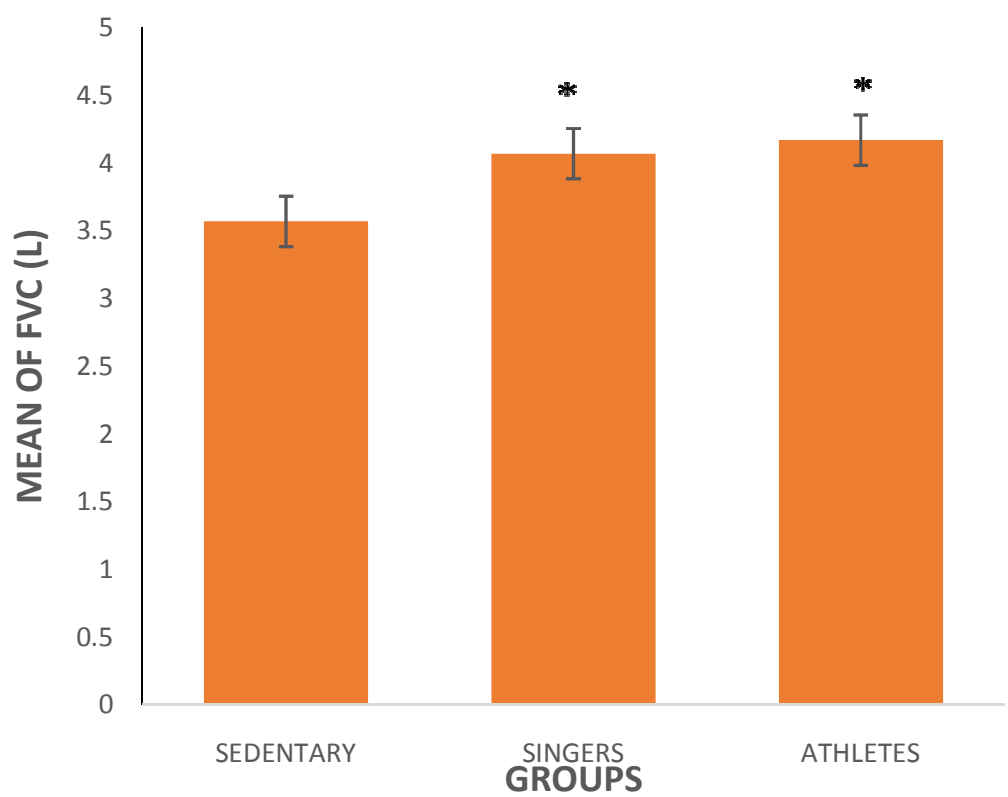

Figure 2: Mean for FVC among sedentary, singers and athletes. Values presented as mean $\pm S E M, n=20 . *=$ Significant difference at $\mathrm{P}<0.05$ compared to sedentary group 
Bajopas Volume 10 Number 2 December, 2017

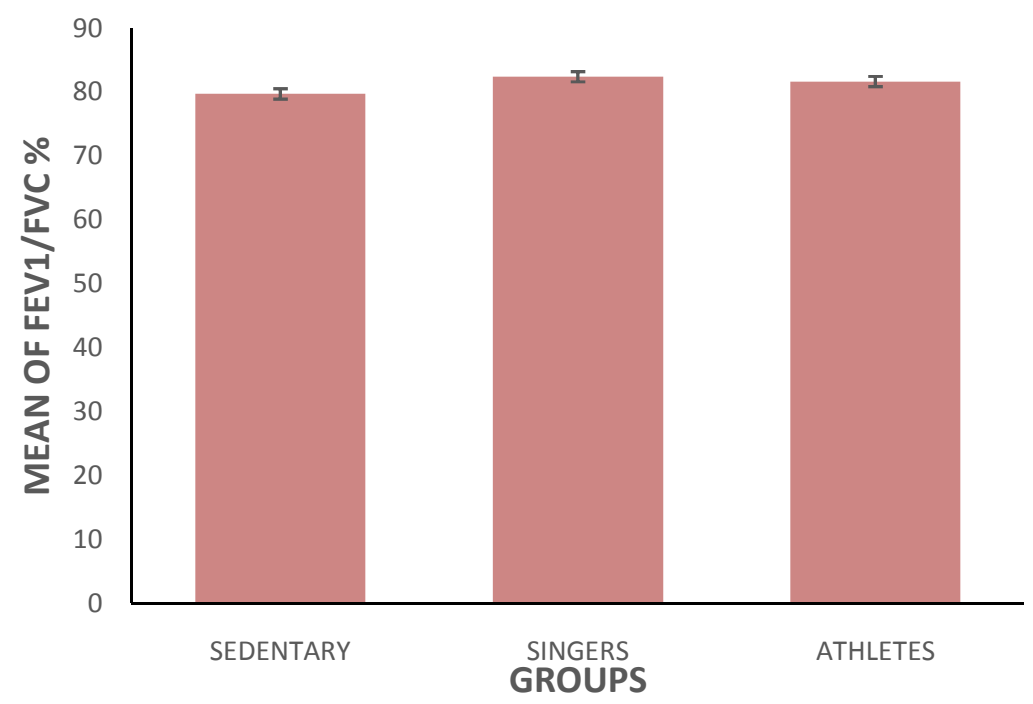

Figure 3: Mean for $\mathrm{FEV}_{1} / \mathrm{FVC} \%$ among sedentary, singers and athletes. Values presented as mean $\pm \mathrm{SEM}$, $\mathrm{n}=20{ }^{*}=$ Significant difference at $\mathrm{P}<0.05$ compared to sedentary group

\section{DISCUSSION}

The increase in metabolic activities during physical activity improve pulmonary function by increasing pulmonary capacity as the strength of respiratory muscles are increased.The results of the present study showed that both singers and athletes had abetter lung function than the sedentary group. This is evident in the significantly higherFEV ${ }_{1}$ and FVCthan that for sedentary group.Akhade and Muniyappanar(2014);Sable, et al. (2012), andVedala, et al.(2013), also observedhigherFEV ${ }_{1}$ and FVC in athletes than in sedentary groups. The difference between athletes and singers was of no statistical significance. This supports the study of Prakash et al.(2007) who compared two different physical activities and found athletes and yogis to have a higher pulmonary function compared to the sedentary group.

The difference among the groups for $\mathrm{FEV}_{1} / \mathrm{FVC} \%$ were not statistically significant.Akhade and Muniyappanar(2014) also made a similar observation in there study. Even though not significant, singers had the highest $\mathrm{FEV}_{1} / \mathrm{FVC}$ ratio. This could be related to the depth and intensity of respiratory manoeuvres involved in phonation and vocalization in singing. It has also been observed that some particular sport disciplines improve the lung function better than others, these include swimming, basketball, water polo and rowing (Lazovic et. al. 2015; Doherty \& Dimitriou, 1997). Lazorovic-Popovic et al.2016 also found swimmers to have a higher $\mathrm{FEV}_{1} / \mathrm{FVC}$ ratio than footballers and sedentary control individuals.

\section{REFERENCES}

Adegoke, O. A., \& Arogundade, O. (2002). The effect of chronic exercise onlung function and basal metabolic rate in some Nigerian athletes. African Journalof Biomedical Research, 5(12), 9-11.

Attarzadeh, S.R., Hejazi, S.M,\& Soltani, H. (2006). The effect of selected aerobic exercise program on pulmonary volumes and
Physiological determinants of lung volumes/capacities are age, gender, anthropometric measures, ethnicity, altitude and physical activities. When matched with anthropometric data, our study showed a positive correlation between pulmonary functions and anthropometric features. Singersand athletes who had higher $\mathrm{FEV}_{1}$ andFVC than sedentary group also had greater mean weights than sedentary group. This was also observed by Lazorovic-Popovic et al.in 2016.

The conflicting finding in some studies may be due to genetic and ethnic factors as seen in lung function amongst athletes in different Indian populations (Lakhera \& Kain, 1995) and in different settings with results suggesting that the size of lung is governed by genetic, environmental and nutritional factors (Lakhera et al., 1984).

\section{CONCLUSION}

The study showed a better pulmonary function in both athletes and singers compared to sedentary control with a positive correlation to weight. Singers did not differ in pulmonary functions when compared to athletes.

\section{AUTHOR CONTRIBUTIONS}

The authors together are responsible for the design of the study, statistical analysis and writing of the manuscript.

\section{CONFLICT OF INTEREST}

The authors declare no conflict of interest.

\section{ACKNOWLEDGEMENTS}

The authors are very grateful to the participants and the technical staff of the laboratory of the Department of Human Physiology, Ahmadu Bello University Zaria the technical assistance.

capacities of nonathlete male students. International congress on physical education and sport science. 21-23, Iran.

Akhade, V., \& Muniyappanavar, N. S. (2014). The effect of running training on pulmonary function tests. National Journal of Physiology, Pharmacy and Pharmacolgy, 4(2), 168-170. 
Belman, M.J., \& Mittman, C. (1980). Ventilatory muscle training improves exercise capacity in chronic obstructive pulmonary disease patients. American Review of Respiratory disease,121(2), 273-279.

Collyer, S., Thrope, C. W., Callaghan, J.,\& Davis, P. J. (2008). The influence of fundamental frequency and sound pressure level range on breathing patterns in female classical singing. Journal of Speech, Language and Hearing Research, 51, 612-28.

Doherty, M., \& Dimitriou, L. (1997). Comparison of lung volume in Greek swimmers, land based athletes, and sedentary controls using allometric scaling. British Journal of Sports Medicine, 31, 337-341.

Hamilton, P., \&Andrew, G. M. (1976). Influence of growth and athletic training on heart and lung functions. European Journal of Applied Physiology and Occupational Physiology, 36(1), 27-28.

Johnson, J., Theurer, W. M. (2014).A stepwise approach to the interpretationof pulmonary function tests. American Family Physician, 89(5), 359-366.

Kuppu Rao, V. K., \& Vijayan, V. K. (1998). Maximum expiratory flow volume loop in southern Indian college sportsmen. Indian Journal of Physiology and Pharmacology,32(2), 93-99.

Lakhera, S.C., \& Kain, T.C. (1997). Comparison of pulmonary function amongst Ladakhi, Delhi, Varanasi and Siddhi female athletes.Indian Journal of Physiology and Pharmacology, 41(1), 52-56.

Lakhera, S.C., Mathew, L., Rastogi, S. K., \& Sen Gupta., J. (1984). Pulmonary function of Indian athletes and sportmen: Comparison with American athletes. Indian Journal of Physiology and Pharmacology, 28(3), 18794.

Lazovic, B., Mazic, S., Suzic-Lazic, J., Djelic, M., Djordjevic-Saranovic, S., Durmic, T., Zikic, D., \& Zugic, V. (2015). Respiratory adaptations in different types of sport. European Review for Medical and Pharmacological Sciences, 19(12), 22692274.

Lazovic-Popovic, B., Zlatkovic-Svenda, M., Durmic, T., Djelic, M, Djordjevic-Saranovic, S., \& Zugic, V. (2016). Superior lung capacity in swimmers: Some questions, more answers!Revista Portuguesa de Pneumologia,22(3), 151-156.

Lutfi, M. F. (2017). The physiological basis and clinical significance of lung volume measurements. Multidisciplinary Respiratory Medicine, 12(3).

Miller, M.R., Crapo, R., Hankinson, J., Brusasco, V., Burgos F., Casaburi, R., ...Wanger, J (2005a). General considerations for lung function testing. European Respiratory Journal, 26(1), 153-161.

Miller, M.R., Crapo, R., Hankinson, J., Brusasco, V., Burgos F., Casaburi, R., ...Wanger, J (2005b). Standardisation of spirometry.
European Respiratory Journal, 26(2), 319338.

Moore, V. C. (2012). Spirometry: Step by Step. Breathe 8(3), 232-240.

Nourry, C., Deruelle, F., Guinhouya, C., Barquet, G., Fabre, C., Bart, F., ...Mucci, P. (2005). High intensity intermittent running training improves pulmonary function and alters exercise breathing pattern in children. European Journal of Applied Physiology, 94(4), 415-423.

Pellegrino, R., Viegi, G., Brusasco, V., Crapo, R. O., Burgos, F., Casaburi, R., Coates, A.,

...Wanger, J. (2005). Interpretative strategies for lungfunction tests. European Respiratory Journal, 26(5), 948-968.

Pettersen, V., (2005). Muscular patterns and activation levels of auxiliary breathing muscles and thorax movement in classical singers. FoliaPhoniatrica et Logopaedica, 57(5-6), 256-77.

Prakash, S., Meshram, S., \& Ramtekkar, U. (2001). Athletes, Yogis and individuals with sedentary life styles: Do their lung volumes differ? Indian Journal of and Pharmacology, 51(1), 76-80.

Ranu, H., Wilde, M., \&Madden, B. (2011). Pulmonary function tests. Ulster Medical Journal, 80(2), 84-90.

Robinson, E.P.,\& Kjeldgard, J.M., (1982). Improvement in ventilatory muscle function with running.Journal of Applied Physiology: respiratory, environmental and exercise physiology, 52(6), 1400-1406.

Sable, M. S., Sable, S. S., Zingade, U. S., \& Kowale, A. N. (2012). Preliminary study of lung function in athletes and nonathletes in Marathwada region. International Journal on Current Research and Review, 4(21), 57-63.

Vedala, S., Paul, N., \& Mane, A. B. (2013). Differences in pulmonary function test among the athletic and sedentary population. National Journal of Physiology, Pharmacy \& Pharmacology, 3(2), 118-123.

Vestbo, J., Hurd, S. S., Agustí, A. G., Jones, P. W., Vogelmeier, C., Anzueto, A., Barnes, P. J, Fabbri, L. M, ....Rodriguez-Roisin, R. (2013). Global strategy for the diagnosis,management, and prevention of chronic obstructive pulmonary disease:GOLD executive summary. American Journal of Respiratory and Critical Care Medicine, 187(4), 347-365.

Wassermann, K., Gitt, A., Weyde, I., \& Eckel, H.E. (1995). Lung function changes and exerciseinduced ventilatory responses to external restive loads in normal subjects. Respiration, 62(4), 177-84. 